\title{
KNOWLEDGE, ATTITUDES, BELIEFS AND PRACTICES OF OCCUPATIONAL PHYSICIANS TOWARDS VACCINATIONS OF HEALTH CARE WORKERS: A CROSS SECTIONAL PILOT STUDY IN NORTH-EASTERN ITALY
}

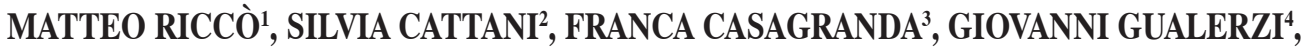 and CARLO SIGNORELLI ${ }^{5}$}

${ }^{1}$ Provincial Agency for Health Services, Trento, Italy

Department of Prevention, Occupational Health and Safety Unit

${ }^{2}$ University of Parma, Parma, Italy

School of Nursing Sciences, Department of Clinical Surgery, General Surgery and Surgical Therapy

${ }^{3}$ Provincial Agency for Health Services, Trento, Italy

Department of Prevention, Unit for Health Promotion and Education, Lifestyle Surveillance

${ }^{4}$ University of Parma, Parma, Italy

School of Medicine and Surgery, Department of Clinical and Experimental Medicine

${ }^{5}$ University of Parma, Parma, Italy

Department of Biomedical, Biotechnological, and Translational Sciences (SBiBiT)

\begin{abstract}
Objectives: This study aims to characterize personal attitudes and knowledge of a sample of Italian occupational physicians (OPhs) towards immunization practice in the case of healthcare workers (HCWs). Material and Methods: A total of $90 \mathrm{OPhs}(42.2 \%$ of males, $57.8 \%$ of females, mean age of $50.1 \pm 8.3$ years old) compiled a structured questionnaire through a telephonic interview. They were asked about the official Italian recommendations for HCWs, their general knowledge of vaccine practice, their propensity towards vaccines (both in general and about specific immunizations), their risk perception about the vaccine-preventable infectious diseases. Eventually, a regression analysis was performed in order to identify factors predictive for vaccine propensity. Results: Only 12 out of 90 subjects correctly identified all the 7 recommended immunizations. The hepatitis B virus (HBV) vaccine was correctly identified by $95.6 \%$ of the sample, and was also associated with the more positive attitude and the more accurate risk perception. Influenza vaccine had the lowest acceptance $(75.9 \%)$. Eventually, pertussis, measles, parotitis and varicella vaccines were insufficiently recognized as
\end{abstract}

Received: January 18, 2016. Accepted: August 22, 2016.

Corresponding author: M. Riccò, Provincial Agency for Health Services, Department of Prevention, Occupational Health and Safety Unit, Viale Verona SNC (C/O Big Center), 38123 Trento, Italy (e-mail: mricco2000@gmail.com). 
recommended ones (all cases $<50 \%$ of the sample). General knowledge of vaccine and knowledge of official recommendations were significantly correlated with the attitude towards immunization practice $(\mathrm{r}=0.259, \mathrm{p}=0.014$ and $\mathrm{r}=0.438$, $p<0.0001$ ). In the regression analysis general knowledge (unstandardized coefficient $(B)=0.300$, 95\% confidence interval $(\mathrm{CI}): 0.090-0.510, \mathrm{p}=0.006)$ and risk perception $(\mathrm{B}=0.579,95 \% \mathrm{CI}: 0.155-1.003, \mathrm{p}=0.008)$ were significant predictors of the propensity to vaccinate. Conclusions: Vaccinations gaps in HCWs may found their roots in OPhs incomplete knowledge of evidence-based recommendations. Specific training programs and formations courses should then be planned. Int J Occup Med Environ Health 2017;30(5):775-790

Key words:

Occupational infection, Healthcare workers, Immunization, Occupational physician, Vaccination recommendation, Vaccine hesitancy

\section{INTRODUCTION}

Healthcare workers (HCWs) are at increased risk of acquiring and transmitting communicable diseases due to their occupational exposure to patients and bodily fluids [1]. As many of these diseases may transmit during the incubation period, or manifest with atypical symptoms, vaccines remain the most cost-effective available preventive measure. Specific vaccination policies of HCWs are therefore justified in order to protect both the workers and their patients against several biologic risk agents [2-7], delivering significant cost savings for healthcare organizations [8-10]. Vaccination policies for HCWs should then be integrated in all the healthcare settings. In Italy, for instance, specific recommendations for $\mathrm{HCWs}$ are issued by the Ministry of Health issues through the National Immunization Prevention Plan (Piano Nazionale di Prevenzione Vaccinale - PNPV), a guidance document for immunization policies [11]. These recommendations provide advice regarding the vaccinations recommended for HCWs (i.e., hepatitis, influenza, pertussis, measles, mumps, rubella, varicella) as well as the duration of protection after vaccination and need for booster vaccinations [11]. Application of immunization policies for the workplaces is a main issue for Occupational Physicians (OPhs). With specificities stemming from the respective national legislations, OPhs are the medical professionals responsible for health promotion in the workplaces, and contribute to immunizations programs both directly applying and tailoring official recommendations (i.e., PNPV in Italy, Standing Committee on Vaccination (Ständigen Impf- kommission - STIKO) in Germany, etc.) as appropriate vaccination policies. This is of particular importance for some vaccine preventable diseases (VPD); e.g., diphtheria, tetanus and pneumococcal disease), the risk of which for HCWs is usually reputed not greater than in the general population, although some healthcare settings (i.e., acute-care hospitals, intensive-care units, nursing homes, and more specifically HCWs caring subjects vulnerable to severe or complicated infections) may require additional precautions, in particular for respiratory pathogens such as pneumococcus $[2,3,11,12]$.

Moreover, OPhs are directly involved in the communication of risk, participating in the information and formation of the workers [12]: in Italy, Occupational Health and Safety Legislation [13] requires that the OPhs will inquiry vaccination history, recall the vaccination status, and inform the workers about the pros and cons of recommended vaccinations.

Unfortunately, vaccination levels of HCWs in high income countries remain largely insufficient, particularly in Italy [11,14-17]. Assessing the beliefs, attitudes and knowledge of specific occupational groups regarding vaccination may therefore be useful in order to tailor vaccination campaigns and improving vaccination rates [18]. Although numerous studies have assessed why HCWs do not receive the recommended vaccinations [16-20], knowledge, attitudes and practices (KAP) of the $\mathrm{OPh}$ have been scarcely investigated [12]. This is a critical issue, as OPhs are not only HCWs themselves (being therefore directly involved in the potential chain of transmission) but they also per- 
form and promote vaccinations, and may implement acceptance and knowledge among other HCWs [12]. Appropriate interventions on OPhs may then maximize the consent for vaccination programs, contributing to overcome the mutual misunderstanding between public health professionals and vaccine hesitant individuals or even vaccine objectors.

Therefore, the main endpoint of this study is to assess KAP of OPhs about vaccinations and vaccination policies. In particular, we explored both general and specific recommendations for HCWs, and how KAP relate to these recommendations. Moreover, as several uncertainties still remain regarding the implementation of pneumococcus vaccination among HCWs, this topic has been specifically evaluated. Eventually, our results may be useful in order to identify areas that may be targeted for improvement through specific informative and educative campaigns dedicated to OPhs.

\section{MATERIAL AND METHODS}

\section{Study design}

In this cross-sectional questionnaire study, OPhs operating in the Autonomous Province (AP) of Trento, Italy, were asked about their knowledge and attitudes towards vaccination [21,22]. In particular, we tested specific knowledge and attitudes of OPhs regarding vaccinations recommended for HCWs by the PNPV 2012-2014 [11].

\section{Study population}

A seminar on occupational health took place in the AP of Trento in October 2015. All participating OPhs with specialization in occupational medicine $(\mathrm{N}=106)$, and assisting at least one healthcare provider in the AP of Trento were asked whether they would agree to participate in a survey about knowledge and attitudes towards vaccinations. The collected sample included 95 professionals, representing the $39.7 \%$ of all $\mathrm{OPh}$ operating in the AP of Trento by December 2015 ( $\mathrm{N}=239,183$ males,
56 females; age $($ mean $(\mathrm{M}) \pm$ standard deviation $(\mathrm{SD}))=$ $51.6 \pm 10.6$ years old). All subjects agreeing to participate were informed they would receive a telephonic interview in the following weeks.

\section{Ethical considerations}

Before they gave their consent, participants had been informed that all information would be gathered anonymous and handled confidentially. Participation was voluntary, and the questionnaire was collected only from subjects who had expressed consent for study participation. As individual participants cannot be identified based on the presented material, this study caused no plausible harm or stigma to participating individuals. Eventually, no preliminary evaluation by the Ethical Committee was reputed necessary.

\section{Questionnaire}

Two specifically formed healthcare professionals compiled a structured questionnaire through a telephonic interview. All surveys were conducted between November and December 2015.

As duties and responsibilities of OPhs are substantially similar in Italy and Germany, and also National recommendations for vaccinations in HCWs are quite similar, our inquiry was performed through an adapted and translated version of the utility previously developed by Zingg and Siegrist, and then reformulated for German OPhs by Betsch and Wicker $[12,22,23]$. The questionnaire comprised some general demographic information (i.e., age, sex, country of origin) and 22 items divided in 4 areas of inquiry.

\section{Knowledge of official vaccination recommendations}

Sixteen vaccine preventable diseases were presented (i.e., diphtheria, tetanus, pertussis, poliomyelitis, viral hepatitis A, viral hepatitis B, influenza, pneumococcus, Haemophilus influenzae, measles, rubella, parotitis, varicella, 
meningococcus, human papillomavirus (HPV), tuberculosis). For each disease, participants indicated whether they thought that PNPV 2012-2014 recommends vaccination for HCWs (possible answers: "yes," "no," "don't know"). Knowledge regarding the official vaccination recommendations was calculated as the sum of correctly and incorrectly marked recommendations: when the occupational physicians correctly indicated a vaccination as recommended or not recommended by PNPV, +1 was added to a sum score, whereas a wrong indication or a "don't know" answer added -1 to the sum score. The National Immunization Prevention Plan 2012-2014 recommends 7 vaccinations for HCWs: pertussis, viral hepatitis B, influenza, measles, rubella, parotitis, varicella [11].

\section{General knowledge}

The original knowledge test developed by Zingg and Siegrist [23] contains true-false statements such as "vaccinations increase the occurrence of allergies" (false) covering some typical misconceptions on vaccination. Both the original test and the revised version applied by Betsch and Wicker interpreted the sum of all incorrect answers as the degree of misconceptions held by the participant [12,2123]. In fact, this test successfully predicted influenza risk perceptions and vaccination intentions in previous studies [12,21-23]. Briefly, a total of 14 statements were presented, and general knowledge was then calculated as the sum of correctly and incorrectly marked recommendations: when the occupational physicians correctly answered, +1 was added to a sum score, whereas a wrong indication or a missing/"don't know" answer added -1 to the sum score.

\section{Risk perception}

In their previous study about attitudes and knowledge of $\mathrm{OPh}$ about vaccinations in the case of HCWs, Betsch and Wicker defined perceived risk as a function of the perceived probability of an event and its expected consequences, and therefore assessed as the mathematical product of subjective probability and disease severity [12,21-24]. We inquired the risk perception of $\mathrm{OPh}$ about 8 infectious diseases usually associated with HCWs (i.e., pertussis, viral hepatitis B, influenza, pneumococcus, measles, rubella, parotitis, varicella), that is the 7 vaccinations recommend by PNPV 2012-2014 and the vaccination for pneumococcus, the introduction of which in the future recommendations was debated at the time of the survey. In particular, we asked the $\mathrm{OPh}$ about the probability of a) presented infections in HCWs and b) vaccine-related adverse effects, and whether they perceived the severity c) of the natural infections and d) of vaccine-related adverse effects. In order to summarize the results, we used a fully labeled 7-point scale (i.e., "almost zero," "low," "rather low," "moderate," "rather high," "high," "very high"). The risk perception score was calculated as cumulative score (i.e., sum) for the 7 vaccines recommended to the HCWs by the PNPV 2012-2014 (i.e., pertussis, viral hepatitis B, influenza, measles, rubella, parotitis, varicella), and for the 7 recommended vaccines plus pneumococcus vaccine. Calculation was obtained through the formula:

$$
\text { risk perception }=\mathrm{I}^{\mathrm{INF}} \times \mathrm{C}^{\mathrm{INF}}-\mathrm{I}^{\mathrm{VAC}} \times \mathrm{C}^{\mathrm{VAC}}
$$

where:

$\mathrm{I}^{\mathrm{INF}}$ - perceived probability of infection in the case of HCWs, $\mathrm{C}^{\mathrm{INF}}$ - perceived consequence of infection in the case of $\mathrm{HCW}$, $\mathrm{I}^{\mathrm{VAC}}$ - perceived probability of vaccine-related adverse effects, $\mathrm{C}^{\mathrm{VAC}}$ - perceived consequence of vaccine-related adverse effects.

\section{Attitudes}

Attitudes towards vaccinations were assessed both in general and in particular. Initially, participants were asked about their immunization status. Completed and upto-date vaccination was defined as follows: one shot for rubella, Bacillus Calmette-Guérin (BCG), H. influenzae, pneumococcus, meningococcus, and seasonal influen- 
za, 2 shots for measles, mumps, varicella, or hepatitis A, 4 shots for poliomyelitis, and 3 shots for HPV, hepatitis B (all shots within the appropriate time schedule for each disease), and one booster shot against pertussis and tetanus-diphtheria within the last 10 years. Subsequently, $\mathrm{OPh}$ rated their general attitudes towards vaccinations through a 7-point scale (i.e., "absolutely against vaccinations," "strongly against vaccinations," "somewhat against vaccinations," "neutral," "somewhat in favor of vaccinations," "strongly in favor of vaccinations," "absolutely in favor of vaccinations"). Finally, participants rated their specific propensity towards the 16 vaccine-preventable diseases previously presented (i.e., diphtheria, tetanus, pertussis, poliomyelitis, viral hepatitis A, viral hepatitis B, influenza, pneumococcus, $H$. influenzae, measles, rubella, parotitis, varicella, meningococcus, HPV, tuberculosis) through a 5 points on Likert scale (i.e., 1 - strongly disagree; 2 - disagree; 3 - neutral; 4 - agree; and 5 - strongly agree). A cumulative score (i.e., "propensity score") was calculated as the sum of the single attitudes: in general (all presented vaccines), for HCWs recommended vaccines, and for the $7 \mathrm{HCWs}$ recommended vaccines plus pneumococcus vaccine, in order to directly compare the risk perception and attitude toward these vaccinations.

\section{Data analysis}

Two independent researchers, one of whom read the responses from each questionnaire while the other researcher reviewed the entered data, ensured the accuracy of data entry. The primary investigator examined unclear responses to determine the correct answer. We calculated the described indices for general knowledge, knowledge about PNPV, risk perception and general knowledge, which assess the extent to which physicians pass on official recommendations to their patients. In order to more easily compare the scales, all results were normalized to unity (min. 0.0, $\max 1.0$ ).

Continuous variables were expressed as $\mathrm{M} \pm \mathrm{SD}$. Categorical variables were reported as per cent values. Univariate confrontation between proportions were evaluated through the $\mathrm{Chi}^{2}$ test (with continuity correction) whereas continuous variables were performed through Student's t-test for unpaired data or ANOVA when appropriate. Comparisons of propensity and risk perception scores through ANOVA required the post hoc Dunnett's test. Since hepatitis B virus (HBV) vaccine has been repetitively recognized as well accepted, and the potential consequences of $\mathrm{HBV}$ infection are similarly well known among HCWs, attitudes and risk perception regarding this specific immunization have been assumed as the referent ones. Relations between the continuous variables were explored through the calculation of the Pearson product-moment correlation coefficient (i.e., Pearson's r). In regression analyses (SPSS 23, IBM Corp. Armonk, USA), we assessed the relative influence of attitudes, including self-reported immunization status, general knowledge, and knowledge about recommendations on both the recommendation score and the reported vaccinations. In the analyses, we controlled for age, sex and ethnicity (i.e., Italian born vs. non-Italian born people). Significance level was $5 \%$.

\section{RESULTS}

\section{Descriptive analysis}

Eventually, 90 out of $95 \mathrm{OPh}(94.7 \%$; $89.6 \%$ of the original sample) participated to the inquiry: 38 (42.2\%) were males, and $52(57.8 \%)$ females, with a mean age of $50.1 \pm 8.3$ years.

\section{Assessment of Vaccine Knowledge}

After normalization, the mean Vaccine Knowledge score was $0.57 \pm 0.18$ (range 0.06-1.00) (Table 1). Overall, 12/90 $(13.3 \%)$ recalled all the 7 recommended vaccines, and $35 / 90(38.9 \%)$ were able to identify at least 5 out of 7 recommended HCWs immunizations. Eventually, 42/90 $(46.7 \%)$ recalled only 2 or even less of the recommended vaccines (Figure 1). The most frequently recalled recommended vaccination was HBV (86/90, 95.6\%), followed by 
Table 1. Italian occupational physicians' (OPhs) knowledge of the vaccinations recommended by PNPV 2012-2014 for healthcare workers (HCWs), 2015

\begin{tabular}{|c|c|c|c|c|}
\hline \multirow[t]{2}{*}{ Vaccination } & \multirow{2}{*}{$\begin{array}{l}\text { Official PNPV 2012-2014 } \\
\text { recommendation regarding HCWs }\end{array}$} & \multicolumn{3}{|c|}{$\begin{array}{c}\text { Respondents' answers } \\
(\mathrm{N}=90) \\
{[\mathrm{n}(\%)]}\end{array}$} \\
\hline & & correct & incorrect & $\begin{array}{l}\text { no answer/ } \\
\text { don't known }\end{array}$ \\
\hline Diphtheria & not recommended & $49(54.5)$ & $35(38.9)$ & $6(6.7)$ \\
\hline Tetanus & not recommended & $24(26.7)$ & $64(71.1)$ & $2(2.2)$ \\
\hline Pertussis & recommended & $26(28.9)$ & $57(63.3)$ & $7(7.8)$ \\
\hline Poliomyelitis & not recommended & $50(55.6)$ & $35(38.9)$ & $5(5.6)$ \\
\hline Viral hepatitis A & not recommended & $62(68.9)$ & $23(25.6)$ & $5(5.6)$ \\
\hline Viral hepatitis B & recommended & $86(95.6)$ & $2(2.2)$ & $2(2.2)$ \\
\hline Influenza & recommended & $80(88.9)$ & $8(8.9)$ & $2(2.2)$ \\
\hline Pneumococcus & not recommended & $62(68.9)$ & $20(22.2)$ & $8(8.9)$ \\
\hline Haemophilus influenzae & not recommended & $65(72.2)$ & $11(12.2)$ & $14(15.6)$ \\
\hline Measles & recommended & $40(44.4)$ & $45(50.0)$ & $5(5.6)$ \\
\hline Rubella & recommended & $37(41.1)$ & $48(53.3)$ & $5(5.6)$ \\
\hline Parotitis & recommended & $37(41.1)$ & $47(52.2)$ & $6(6.7)$ \\
\hline Varicella & recommended & $22(24.4)$ & $62(68.9)$ & $6(6.7)$ \\
\hline Meningitis & not recommended & $63(70.0)$ & $19(21.1)$ & $8(8.9)$ \\
\hline Human papillomavirus & not recommended & $80(88.9)$ & $2(2.2)$ & $8(8.9)$ \\
\hline Tuberculosis & not recommended & $38(42.2)$ & $48(53.3)$ & $4(4.4)$ \\
\hline
\end{tabular}

PNPV - Piano Nazionale di Prevenzione Vaccinale (National Immunization Prevention Plan) [11].

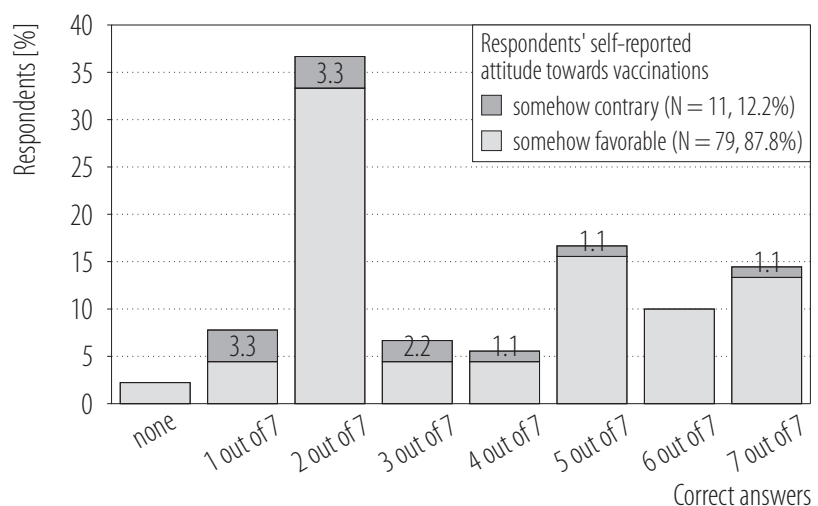

PNPV - Piano Nazionale di Prevenzione Vaccinale (National Immunization Prevention Plan) [11].

Fig. 1. Italian occupational physicians (OPhs) $(\mathrm{N}=90)$ who correctly recalled vaccinations recommended by PNPV 2012-2014 for healthcare workers (HCWs), 2015 influenza $(80 / 90,88.9 \%)$ whereas less than half of the sample $(42 / 90,46.7 \%)$ knew that there was no special recommendation for the vaccination against tuberculosis. Moreover, around $20 \%$ of the sample incorrectly indicated that there were recommendations to vaccinate $\mathrm{HCWs}$ against pneumococcus $(20 / 90,22.2 \%)$ and meningococcus $(19 / 20$, $21.1 \%)$.

After normalization, the range of the General Knowledge score was $0.18-0.89$, with a mean of $0.71 \pm 0.15$. In particular, 47/90 (52.2\%) failed to identify the vaccine additives as not dangerous for human health, with several subjects causatively associating vaccines with neurological diseases such as subacute sclerosing panencephalitis (27/90, $30 \%)$, lethargic encephalitis $(17 / 90,18.9 \%)$, and even au- 
tism $(16 / 90,17.8 \%)$, and autoimmune diseases in general $(23 / 90,25.6 \%)$, the latter including in particular multiple sclerosis $(12 / 90,13.3 \%)$. Moreover, around a third of the sample exhibited misconceptions regarding vaccine practices, as $37 / 90(41.1 \%)$ believed that many vaccinations were administered too early, and 27/90 (30\%) that the immune system may be overwhelmed by the high number of vaccines identified by the vaccine schedules.

\section{Assessment of attitudes}

In general, 79/90 OPhs self-rated their attitude towards vaccinations as somehow favorable (Figure 2). The Table 2 shows self-reported vaccination rates among $\mathrm{OPh}$. In details, highest vaccination rates were reported against poliomyelitis (98.8\%), tetanus (97.8\%) and HBV (86.7\%) whereas the lowest were identified for pneumococcus (5.6\%) and HPV (3.8\% of female subjects). Attitudes to-

Table 2. Attitude of the Italian occupational physicians (OPhs) towards vaccinations in general (5 points Likert scale), 2015

\begin{tabular}{|c|c|c|c|c|c|c|}
\hline \multirow[t]{2}{*}{ Vaccination } & \multirow{2}{*}{$\begin{array}{c}\text { Respondents } \\
\text { somehow favorable } \\
\text { towards vaccinations } \\
(\mathrm{N}=90) \\
{[\mathrm{n}(\%)]}\end{array}$} & \multicolumn{2}{|c|}{$\begin{array}{l}\text { Propensity score } \\
\quad(0.0-1.0)\end{array}$} & \multicolumn{3}{|c|}{$\begin{array}{l}\text { Respondents with self-assessed } \\
\text { immunization status } \\
(\mathrm{N}=90) \\
{[\mathrm{n}(\%)]}\end{array}$} \\
\hline & & $\mathrm{M} \pm \mathrm{SD}$ & $\min .-\max$ & positive & negative & $\begin{array}{c}\text { not } \\
\text { determined }\end{array}$ \\
\hline Diphtheria & $82(91.1)^{* *}$ & $0.944 \pm 0.159$ & $0.200-1.000$ & $64(71.1)$ & $16(17.8)$ & $10(11.1)$ \\
\hline Tetanus & $88(97.8)$ & $0.978 \pm 0.076$ & $0.600-1.000$ & $88(97.8)$ & $2(2.2)$ & - \\
\hline Pertussis & $72(80.0)^{* *}$ & $0.860 \pm 0.202$ & $0.200-1.000$ & $37(41.1)$ & $36(40.0)$ & $17(18.9)$ \\
\hline Poliomyelitis & $86(95.6)$ & $0.964 \pm 0.118$ & $0.200-1.000$ & $89(98.8)$ & $1(1.1)$ & - \\
\hline Viral hepatitis A & $69(76.7)^{*}$ & $0.827 \pm 0.185$ & $0.200-1.000$ & $24(26.7)$ & $61(67.8)$ & $5(5.6)$ \\
\hline Viral hepatitis B & $84(93.3)$ & $0.940 \pm 0.139$ & $0.400-1.000$ & $78(86.7)$ & $10(11.1)$ & $2(2.2)$ \\
\hline Influenza & $62(68.9)^{* *}$ & $0.758 \pm 0.257$ & $0.200-1.000$ & $39(43.3)$ & $49(54.4)$ & $2(2.2)$ \\
\hline Pneumococcus & $65(72.2)$ & $0.820 \pm 0.201$ & $0.200-1.000$ & $5(5.6)$ & $76(84.4)$ & $9(10.0)$ \\
\hline Haemophilus influenzae & $63(70.0)$ & $0.791 \pm 0.212$ & $0.200-1.000$ & $8(8.9)$ & $77(85.6)$ & $5(5.6)$ \\
\hline Measles & $78(86.7)$ & $0.871 \pm 0.195$ & $0.200-1.000$ & $31(34.4)$ & $49(54.4)$ & $10(11.1)$ \\
\hline Rubella $^{a}$ & $82(91.1)$ & $0.902 \pm 0.159$ & $0.200-1.000$ & $26(50.0)$ & $24(46.2)$ & $2(3.8)$ \\
\hline Parotitis & $74(82.2)^{*}$ & $0.860 \pm 0.198$ & $0.200-1.000$ & $20(22.2)$ & $60(66.7)$ & $10(11.1)$ \\
\hline Varicella & $67(74.4)$ & $0.809 \pm 0.210$ & $0.200-1.000$ & $15(16.7)$ & $68(75.6)$ & $7(7.8)$ \\
\hline Meningitis & $81(90.0)$ & $0.887 \pm 0.153$ & $0.400-1.000$ & $10(11.1)$ & $74(82.2)$ & $6(6.7)$ \\
\hline Human papillomavirus ${ }^{\mathrm{a}}$ & $62(68.9)$ & $0.796 \pm 0.212$ & $0.200-1.000$ & $2(3.8)$ & $48(92.4)$ & $2(3.8)$ \\
\hline Tuberculosis & $77(85.6)$ & $0.827 \pm 0.183$ & $0.200-1.000$ & $53(58.9)$ & $30(33.3)$ & $7(7.8)$ \\
\hline All vaccines & - & $0.865 \pm 0.135$ & $0.325-1.000$ & - & - & - \\
\hline All HCWs recommended vaccinations ${ }^{b}$ & - & $0.857 \pm 0.161$ & $0.314-1.000$ & - & - & - \\
\hline
\end{tabular}

$\mathrm{M}$ - mean; SD - standard deviation; min. - minimal value; $\max$ - maximal value.

${ }^{\text {a }}$ Self-assessed immunization status was determined only in subjects of female sex $(\mathrm{N}=52)$.

${ }^{\text {b }}$ Pertussis, viral hepatitis B, influenza, measles, rubella, parotitis, varicella.

${ }^{\mathrm{c}}$ Cumulative score (i.e., propensity score) was calculated as the sum of the single attitudes.

* Correlation between vaccine status and propensity towards vaccination: $\mathrm{p}<0.05$.

** Correlation between vaccine status and propensity towards vaccination: $p<0.01$. 


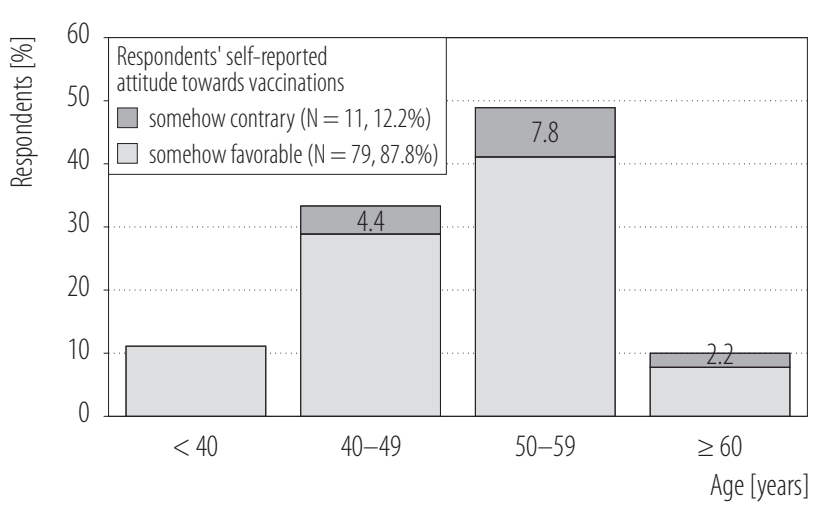

Fig. 2. Italian occupational physicians' (OPhs) $(\mathrm{N}=90)$ self-rated attitude towards vaccinations in general by age groups, 2015

wards vaccines for diphtheria, pertussis, influenza (in all cases, $\mathrm{p}<0.001$ ), hepatitis A virus (HAV) and parotitis $(p<0.05)$ were significantly correlated with self-reported immunization status, with increasing vaccination rates in subjects exhibiting a more positive approach to the aforementioned immunization.

Normalized mean propensity score for HCWs recommended vaccines, was $0.857 \pm 0.161$ and for all vaccines $0.865 \pm 0.135$ - when single vaccinations were taken into account, higher propensity score was associated with HBV $(0.940 \pm 0.139)$ and rubella $(0.902 \pm 0.159)$ whereas influenza vaccine had the lower acceptance $(0.758 \pm 0.257)$, and immunizations against measles $(0.871 \pm 0.195)$, pertussis $(0.860 \pm 0.202)$, tuberculosis (TBC) $(0.827 \pm 0.183)$, pneumococcus $(0.820 \pm 0.201)$, and varicella $(0.809 \pm 0.210)$ having intermediates values (Table 2).

The correlation between general knowledge and attitudes and between knowledge of PNPV recommendations and attitudes was $r=0.259(\mathrm{p}=0.014)$ and $\mathrm{r}=0.438$ $(p<0.0001)$, respectively. In other words, greater the knowledge (i.e., less misconceptions and/or less personal attitudes guiding the vaccine decisions), more favorable was the attitude towards vaccinations. Moreover, declared propensity was significantly correlated with calculated propensity for all the presented vaccines $(r=0.665$, $\mathrm{p}<0.0001)$ and also for immunizations recommended to HCWs $(r=0.630, p<0.0001)$.

\section{Assessment of the risk perception}

Participants identified similar perception for the frequency and severity of vaccine-related adverse effects for the presented immunizations (mean score: $2.576 \pm 1.001$ and $2.571 \pm 1.208$, respectively; in both cases, ANOVA p value $>0.05)$. Conversely, focusing on the perceived probability of infections, OPhs identified influenza and HBV as the more probable (score of $4.256 \pm 1.370$ and $3.811 \pm 1.437$, respectively), followed by pneumococcus $(3.244 \pm 1.327)$ and measles $(2.898 \pm 1.457)$ whereas infections by HBV and pneumococcus were associated with the most severe perceived consequences $(4.300 \pm 1.249$ and $4.133 \pm 1.342$, respectively) (Figure 3 ). In terms of cumulative risk perception score, $\mathrm{OPh}$ perceived $\mathrm{HBV}$ as the most relevant disease $(0.597 \pm 0.099)$, and the risk perception scores for influenza $(0.579 \pm 0.092)$ and pneumococcus $(0.574 \pm 0.078)$ were not significantly different in ANOVA analysis with Dunnett's post hoc test (all cases $\mathrm{p}>0.05$ ). Conversely, all other presented immunizations were associated with a significantly lower score, in particular for pertussis $(0.521 \pm 0.076)$ and varicella $(0.519 \pm 0.098)$ (Table 3$)$. Risk perception was significantly associated with knowledge of PNPV $(r=0.302, p=0.004)$, general knowledge of vaccines $(r=0.347, p=0.001)$ and in particular with the propensity score $(\mathrm{r}=0.426, \mathrm{p}<0.0001)$.

\section{Regression analysis}

In fact, the regression analysis identified general knowledge (unstandardized coefficient $(\mathrm{B})=0.300,95 \% \mathrm{CI}$ : $0.090-0.510, \mathrm{p}=0.006)$ and the risk perception ( $\mathrm{B}=0.579,95 \% \mathrm{CI}: 0.155-1.003, \mathrm{p}=0.008)$ as significant predictors of propensity score for recommended vaccines in HCWs whereas knowledge of PNPV 2012-2014 was not (B $=0.118,95 \% \mathrm{CI}$ : $-0.055-0.291, \mathrm{p}=0.178)$ (Figure 4). Focusing on the specific immunizations, simi- 

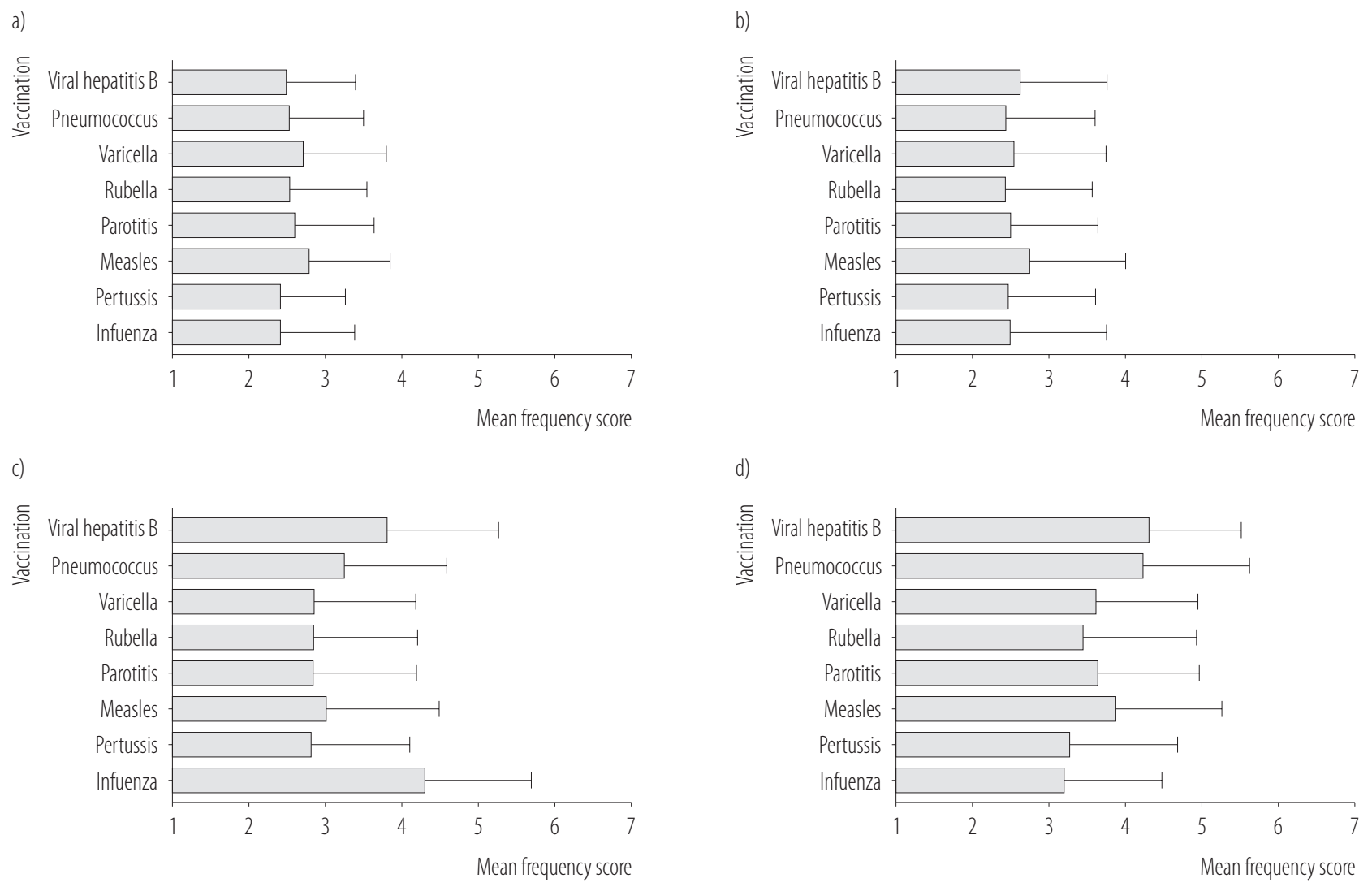

Fig. 3. Italian occupational physicians (OPhs) risk perception score: a) perceived probability and b) consequences of vaccine-related adverse effects, c) perceived probability and d) consequences of infections in healthcare workers (HCWs), 2015

Table 3. Risk perception by the Italian occupational physicians (OPhs) concerning 7 vaccinations recommended by PNPV 2012-2014 for healthcare workers (HCWs) and the vaccination for pneumococcus, 2015

\begin{tabular}{|c|c|c|c|}
\hline \multirow{2}{*}{ Vaccination } & \multicolumn{2}{|c|}{$\begin{array}{l}\text { Propensity score } \\
\quad(0.0-1.0)\end{array}$} & \multirow{2}{*}{$\mathrm{p}$} \\
\hline & $\mathrm{M} \pm \mathrm{SD}$ & $\min .-\max$ & \\
\hline Viral hepatitis B & $0.597 \pm 0.099$ & $0.392-0.938$ & reference \\
\hline Pneumococcus & $0.574 \pm 0.078$ & $0.394-0.862$ & $>0.05$ \\
\hline Varicella & $0.519 \pm 0.098$ & $0.103-0.814$ & $<0.0001$ \\
\hline Rubella & $0.523 \pm 0.098$ & $0.124-0.804$ & $<0.0001$ \\
\hline Parotitis & $0.528 \pm 0.087$ & $0.165-0.804$ & $<0.0001$ \\
\hline Measles & $0.533 \pm 0.103$ & $0.319-0.883$ & $<0.001$ \\
\hline Pertussis & $0.521 \pm 0.076$ & $0.351-0.773$ & $<0.0001$ \\
\hline Influenza & $0.579 \pm 0.092$ & $0.223-0.787$ & $>0.05$ \\
\hline All HCWs recommended vaccinations ${ }^{b}$ & $0.547 \pm 0.074$ & $0.312-0.751$ & \\
\hline
\end{tabular}

Abbreviations as in Tables 1 and 2. 


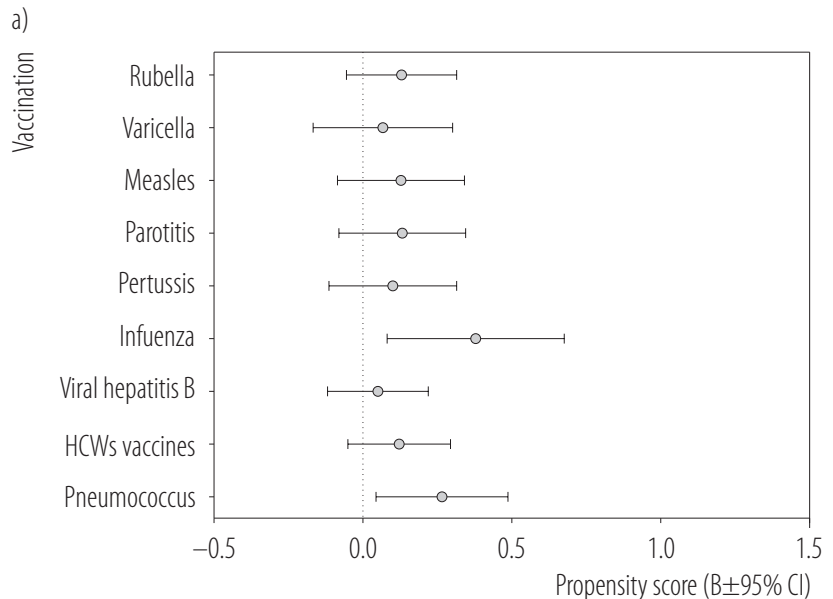

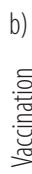

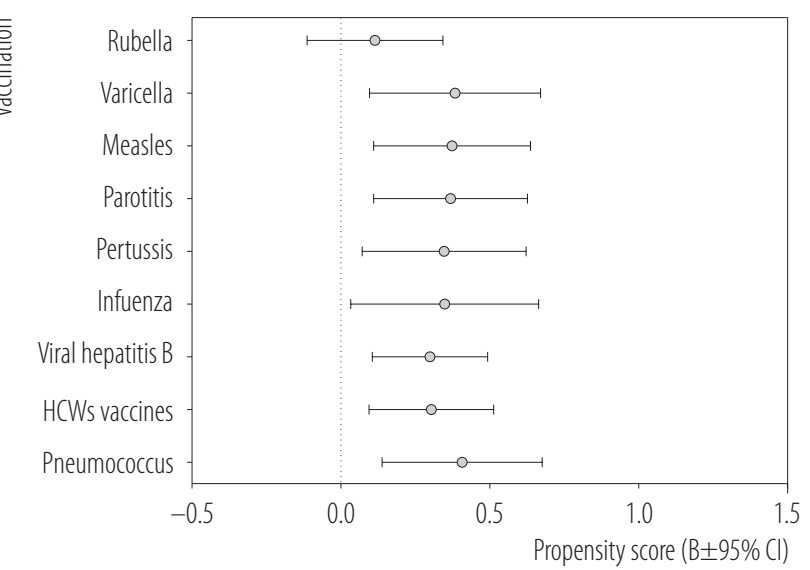

c)

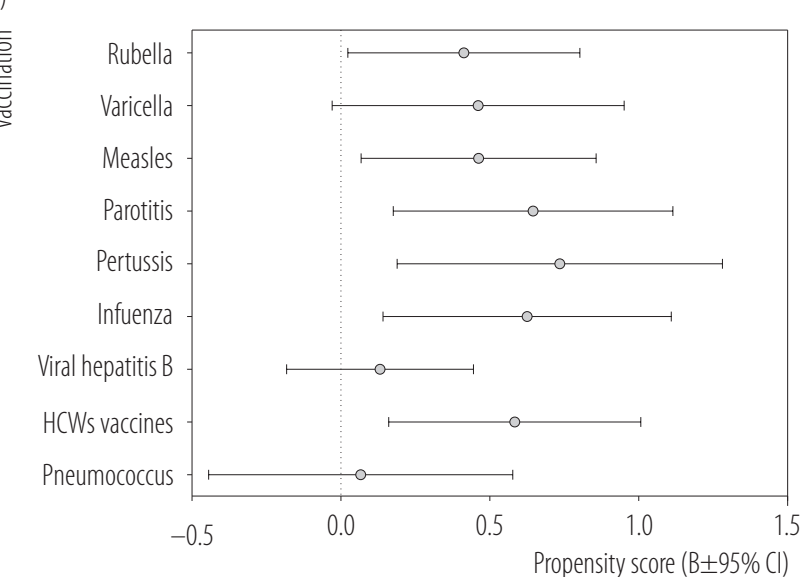

PNPV - Piano Nazionale di Prevenzione Vaccinale (National Immunization Prevention Plan) [11].

HCW - health care worker; B - unstandardized coefficient; $\mathrm{CI}$ - confidence interval.

Fig. 4. Regression analysis was controlled for age at inquiry, sex and ethnicity (i.e., Italian born vs. non-Italian born). lar results were obtained for measles $(\mathrm{B}=0.368,95 \% \mathrm{CI}$ : $0.105-0.631, p=0.007$ and $\mathrm{B}=0.460,95 \%$ CI: $0.065-0.855$, $\mathrm{p}=0.023)$, pertussis $(\mathrm{B}=0.343,95 \%$ CI: 0.067-0.619, $\mathrm{p}=0.015$ and $\mathrm{B}=0.733,95 \% \mathrm{CI}: 0.187-1.279, \mathrm{p}=0.009)$, parotitis $(\mathrm{B}=0.364,95 \% \mathrm{CI}: 0.105-0.623, \mathrm{p}=0.006$ and $\mathrm{B}=0.641,95 \% \mathrm{CI}: 0.172-1.110, \mathrm{p}=0.008)$, and pneumococcus vaccine $(\mathrm{B}=0.262,95 \% \mathrm{CI}: 0.040-0.484, \mathrm{p}=0.021$ and $\mathrm{B}=0.405,95 \% \mathrm{CI}: 0.136-0.673, \mathrm{p}=0.004)$ whereas knowledge of PNPV was identified as the main predictor for the propensity towards influenza and HBV vaccines ( $\mathrm{B}=0.374,95 \% \mathrm{CI}: 0.077-0.651, \mathrm{p}=0.014$ and $\mathrm{B}=0.295$, $95 \%$ CI: 0.102-0.488, $\mathrm{p}=0.003$, respectively).

\section{DISCUSSION}

Given its potential to lead to vaccine delays and refusals, vaccine hesitancy has become a growing focus of attention and concern, and HCWs are not exempted [25-27]. Although there is no strong evidence for a single best strategy to address vaccine hesitancy and refusal [28], several previous reports consistently identified healthcare providers as pivotal in enhancing vaccine acceptance among people who are vaccine hesitant or even refuse vaccinations, and achieving vaccine acceptance and high vaccination rates [29]. Occupational physicians may be understood, regarding immunization practices in the workplace, as healthcare providers of other healthcare providers, and therefore their intervention may be of particular relevance not only for improval of vaccine acceptance among HCWs but also in general population [12].

Unfortunately, with the notable exception represented by HBV vaccination, immunization rates appeared as somehow unsatisfying. In particular, seasonal influenza vaccination coverage was well under $50 \%$ of the sample (43.3\%). Similarly low vaccination rates for influenza, but also VPD such as measles, pertussis, rubella and varicella, were previously reported in other surveys performed in HCWs across Western Europe [30-39]. For instance, influenza vaccination coverage in HCWs in European Countries 
still remains between $14 \%$ and $50 \%$, far below the target objective of $75 \%$ identified by European Centers for Disease Control and the Prevention [40-43]. In Italy, where nationwide updated data was not available, the mean vaccination coverage rate against influenza for HCWs was around $11.5 \%$ in the period 2006-2008, presumptively declining in the following seasons [43].

Low self-assessed vaccination rates were associated with largely positive attitudes towards vaccinations, both in general and regarding vaccines recommended by PNPV 2012-2014 [11]. More specifically, recommendations towards HBV and influenza vaccines were accurately recalled by a significant proportion of the sample $(95.6 \%$ and $88.9 \%$, respectively), with propensity towards HBV approaching the maximum $(0.940 \pm 0.139)$, and even the attitude towards influenza suggested an adequate tough more conditioned acceptance $(0.758 \pm 0.257)$.

Also measles, pertussis, parotitis and rubella vaccines were associated with relatively high or even very high propensity but were correctly identified as recommended ones by less than $30 \%$ of the sample. These specific VPD have recently re-emerged in the European Union (EU) as the result of sub-optimal immunization levels, and an increasing number of official recommendations points towards the implementation of these vaccinations not only in the case of HCWs but also in the general adult schedule [44,45]. Therefore, these results may presumptively be interpreted as the consequent of a communicative and informative gap of OPhs about such vaccinations in HCWs [46-48], and more in general regarding up-to-date medical evidence regarding the morbidity and even the epidemiology of VPD $[15,37,46]$. As a sound evidence suggests that better awareness and greater knowledge of HCWs regarding vaccines increase the propensity to vaccine and to be vaccinated [12,47-50], and also our results suggest general knowledge and risk perception as the main predictors for the vaccination propensity in OPhs, several results from our survey sustain this specific interpretation.
First of all, around $50 \%$ of the sample failed to identify tuberculosis vaccination as not recommended for HCWs despite an active surveillance strategy replaced mandatory vaccination policy for HCWs since 1998 [51] and nearly a fifth of our sample indicated that there were official recommendations towards meningitis and pneumococcus immunizations in the case of HCWs $(21.1 \%$ and $22.2 \%$, respectively). Moreover, propensity score for the latter immunization was also relatively high (i.e., $0.887 \pm 0.153$ ), greater than measles $(0.871 \pm 0.195)$, parotitis $(0.860 \pm$ $0.198)$, varicella $(0.809 \pm 0.210)$ and even influenza.

Likewise, the high vaccination rate for HBV self-referred by OPhs should be underlined, despite these professionals are usually not exposed to invasive procedures at increased risk for blood-borne pathogens. These results are consistent with the previous survey of Betsch and Wicker on OPhs [12], and may be similarly and collectively interpreted in terms of inadequate, incomplete or even inappropriate postgraduate medical education with subjects reporting "common-sense" rather than "evidence based" recommendations. Actually, HBV, tuberculosis, staphylococcal pneumonia and epidemic cerebrospinal meningitides are universally acknowledged as severe and potentially life-threatening infectious diseases, whereas measles, parotitis, varicella and even seasonal influenza are more frequently assumed to be relatively indolent pediatric disorders [12,15,37,46-50], and also in our sample we assessed a relatively lower risk perception (Table 3), in turn determined by a lower severity score for those diseases in confront with pneumococcus and HBV (Figure $3 \mathrm{c}$ and $3 \mathrm{~d}$ ). Regarding seasonal influenza vaccination, our results show a probably more complex habit. Despite the risk perception for influenza infection was relatively high, and similar to the scores reported for HBV and pneumonia, propensity score was conversely low. Focusing on the 4 components of the risk perception score (i.e., perceived probability and severity of infection and vaccinerelated adverse effects), influenza infection in HCWs was 
perceived as highly probable, but its potential severity was not similarly well appreciated. Moreover, it is possible that these results have been affected by the diffuse misunderstandings about the efficacy of the vaccine in disease prevention [16,17], a critical point is well described in previous studies investigating KAP of HCWs towards seasonal influenza vaccine [18,19,39,52-57].

In this regard, the prevalence of false beliefs and misconceptions about vaccines and their side-effects was surprisingly high, in particular for healthcare professionals. The warnings about causative association between vaccines and autoimmune diseases (e.g., multiple sclerosis, diabetes, asthma, etc.; referred by 23/90 sampled OPhs, 25.6\%), and also between MPR vaccine and neurological disorders such as autism $(16 / 90,17.8 \%)$ and subacute sclerosing panencephalitis $(27 / 90,30 \%)$, and influenza vaccine and lethargic encephalitis $(17 / 90,18.9 \%)$, were raised in the previous decades, received diffuse emphasis on the information media, but were criticized or ultimately disproved in the following years $[7,47]$. As vaccine acceptance is significantly influenced by emotional cognitive and social distortions or biases affecting judgment [58], this low propensity towards such vaccinations may be explained not only as a consequence of an incomplete awareness that measles, varicella, influenza and pertussis still remain diseases that may eventually result in severe complications such as acute respiratory failure, encephalitis or even death, and that a significant number of European HCWs are susceptible therefore posing themselves, their patients or colleagues at risk, but also as the sum of alarming misconceptions and poor knowledge of vaccine's benefits and safety $[7,34,46,47,49]$.

Several limits of our study should be accurately stressed. First of all, the study population in our study was relatively small (around 1.4\% of all licensed OPhs in Italy) and not randomly selected. Moreover, we may expect that the "convenience sampling" we applied, including professionals participating to a continuous medical education event, ultimately overestimate both knowledge and attitudes of
OPhs towards immunizations. Finally, Italy has been repetitively acknowledged for very heterogeneous vaccination rates [11]: therefore, our results should be cautiously interpreted as representative of the National level. However, as our sample included the $39.7 \%$ of all OPhs operating in the AP of Trento, it may be interpreted as representative of a local area characterized by a very high degree of socioeconomic development. In fact, our results are consistent with previous studies about HCWs performed in other high income countries, and in particular with the survey on $\mathrm{OPhs}$ recently performed by Betsch and Wicker [12].

In this regard, our study may be of particular interest as the latter study focused mainly on influenza vaccine, with more general evaluation of other vaccines, and encompassed a relatively heterogeneous population of $135 \mathrm{OPh}$ : $56.4 \%$ of subjects had a full 5-year residency whereas $40 \%$ had a minor specialization with 2-year residency and 3.6\% had not yet completed their residency.

On the contrary, we described a sample of OPhs with current expertise in healthcare settings, relatively homogeneous in terms of demography and geographic area of professional activity.

Finally, despite the shared EU directives and guidelines representing the very foundations of all the National legislation, National setting of Italy on Occupational Health and Safety law is neither typical or representative of all developed countries. In this regard it should be stressed that Italian law enforces occupational health surveillance, with occupational health services ultimately available to all HCWs, and their duties specifically include the surveillance for the immunization status $[59,60]$.

Moreover, despite duties and activities of OPhs in continental EU countries are substantially analogous, academic and post-graduate formation of OPhs is not so comparably similar. For instance, in Italy qualification as OPhs is obtained through specialization in occupational medicine but also specialists in hygiene and public health or in legal/forensic medicine may obtain such qualification through fur- 
ther post-degree courses because of a partially shared training $[58,59]$. For this reason, in our sample only subjects specialized in occupational medicine were actually included.

\section{CONCLUSIONS}

In conclusion, our results confirm a generally positive attitude of OPhs towards vaccines and immunization practices. However, the inconsistent attitude towards vaccines against measles, parotitis, varicella and rubella, the high degree of misconceptions eventually reported by the sample, and the relatively low acceptance of influenza vaccine recommend that specific training and educative programs should be targeted in order to achieve a better knowledge of evidencebased recommendations. In particular, transparent communications targeting diffuse false beliefs and misconceptions, and the OPh-tailored interventions could help to build increased trust in the effectiveness and safety of vaccines and in the vaccine policy, ultimately enhancing the contribute of $\mathrm{OPhs}$ to increase vaccination rates and building vaccine acceptance and resiliency in face of the anti-vaccine lobby in HCWs and, subsequently, in general population.

\section{REFERENCES}

1. Brotherton JML, Bartlett MJ, Muscatello DJ, Campbell-Lloyd S, Stewart K, McAnulty JM. Do we practice what we preach? Health care worker screening and vaccination. Am J Infect Control. 2003;31(3):144-50, https://doi.org/10.1067/mic.2003.24.

2. Hayward AC, Harling R, Wetten S, Johnson AM, Munro S, Smedley J, et al. Effectiveness of an influenza vaccine programme for care home staff to prevent death, morbidity, and health service use among residents: Cluster randomised controlled trial. BMJ. 2006;333(7581):1241, https://doi.org/ 10.1136/bmj.39010.581354.55.

3. Lemaitre M, Meret T, Rothan-Tondeur M, Belmin J, Lejonc JL, Luquel L, et al. Effect of influenza vaccination of nursing home staff on mortality of residents: A cluster-randomized trial. J Am Geriatr Soc. 2009;57(9):1580-6, https:// doi.org/10.1111/j.1532-5415.2009.02402.x.
4. Carman WF, Elder AG, Wallace LA, McAulay K, Walker A, Murray GD, et al. Effects of influenza vaccination of health-care workers on mortality of elderly people in long-term care: A randomised controlled trial. Lancet. 2000;355(9198):93-7, https://doi.org/10.1016/S0140-6736 (99)05190-9.

5. Potter J, Stott DJ, Robert MA, Elder AG, O’Donnell B, Knight PV, et al. Influenza vaccination of health care workers in long-term-care hospitals reduces the mortality of elderly patients. J Infect Dis. 1997;175:1-6, https://doi.org/10.1093/ infdis/175.1.1.

6. Salgado CD, Giannetta ET, Hayden FG, Farr B. Preventing nosocomial influenza by improving the vaccine acceptance rate of clinicians. Infect Control Hosp Epidemiol. 2004;25(11):923-8, https://doi.org/10.1086/502321.

7. Maltezou HC, Gargalianos P, Nikolaidis P, Katerelos P, Tedoma N, Maltezos E, et al. Attitudes towards mandatory vaccination and vaccination coverage against vaccinepreventable diseases among health-care workers in tertiarycare hospitals. J Infect. 2012;64(3):319-24, https://doi.org/ 10.1016/j.jinf.2011.12.004.

8. Music T. Protecting patients, protecting healthcare workers: A review of the role of influenza vaccination. Int Nurs Rev. 2012;59(2):161-7, https://doi.org/10.1111/j.1466-7657.2011. 00961.x.

9. Cella MT, Corona G, Tuccillo E, Franco G. [Assessment of efficacy and economic impact of an influenza vaccination campaign in the personnel of a health care setting]. Med Lav. 2005;96(6):483-9. Italian.

10. Ahmed F, Lindley MC, Allred N, Weinbaum CM, Grohskopf L. Effect of influenza vaccination of healthcare personnel on morbidity and mortality among patients: Systematic review and grading of evidence. Clin Infect Dis. 2013;58(1):50-7, https://doi.org/10.1093/cid/cit580.

11. Bonanni P, Ferro A, Guerra R, Iannazzo S, Odone A, Pompa MG, et al. Vaccine coverage in Italy and assessment of the 2012-2014 National Immunization Prevention Plan. Epidemiol Prev. 2015;39(5):145-58. 
12. Betsch C, Wicker S. Personal attitudes and misconceptions, not official recommendations guide occupational physicians' vaccination decisions. Vaccine. 2014;32(35):4478-84, https:// doi.org/10.1016/j.vaccine.2014.06.046.

13. [The Act No. 81 of 9 April 2008 on health and safety in the workplaces. J Laws (GU) 2008, No. 101, ordinary suppl. No. 108]. Italian.

14. Maltezou HC. Nosocomial influenza: New concepts and practice. Curr Opin Infect Dis. 2008;21:337-43, https://doi. org/10.1097/QCO.0b013e3283013945.

15. Botelho-Nevers E, Gautret P, Biellik R, Brouqui P. Nosocomial transmission of measles: An updated review. Vaccine. 2012;30(27):3996-4001, https://doi.org/10.1016/j.vaccine.2012.04.023.

16. Hollmeyer HG, Hayden F, Poland G, Buchholz U. Influenza vaccination of health care workers in hospitals - A review of studies on attitudes and predictors. Vaccine. 2009;27: 3935-44, https://doi.org/10.1016/j.vaccine.2009.03.056.

17. Durando P, Alicino C, Dini G, Barberis I, Bagnasco AM, Iudici R, et al. Determinants of adherence to seasonal influenza vaccination among healthcare workers from an Italian region: Results from a cross-sectional study. BMJ Open. 2016;6:e010779, https://doi.org/10.1136/bmjopen-20 15-010779.

18. Vasilevska M, Ku J, Fisman DN. Factors associated with healthcare worker acceptance of vaccination: A systematic review and meta-analysis. Infect Control Hosp Epidemiol. 2014;35(6):699-708, https://doi.org/10.1086/676427.

19. Hofmann F, Ferracin C, Marsh G, Dumas R. Influenza vaccination of healthcare workers: A literature review of attitudes and beliefs. Infection. 2006;34(3):142-7, https://doi. org/10.1007/s15010-006-5109-5.

20. Dinelli MIS, das Neves Fraga Moreira T, Cruz Paulino ER, Pereira da Rocha MC, Bracale Graciani F, de Moraes-Pinto MI. Immune status and risk perception of acquisition of vaccine preventable diseases among health care workers. Am J Infect Control. 2009;37(10):858-60, https://doi.org/ 10.1016/j.ajic.2009.04.283.
21. Riccò M, Razio B, Panato C, Poletti L, Signorelli C. Knowledge, attitudes and practices of agricultural workers towards tetanus vaccine: A field report. Ann Ig. 2017;29:239-55.

22. Betsch C, Wicker S. E-health use, vaccination knowledge and perception of own risk: Drivers of vaccination uptake in medical students. Vaccine. 2012;30(6):1143-8, https://doi. org/10.1016/j.vaccine.2011.12.021.

23. Zingg A, Siegrist M. Measuring people's knowledge about vaccination: Developing a one-dimensional scale. Vaccine. 2012;30(25):3771-7, https://doi.org/10.1016/j.vaccine.2012. 03.014.

24. Yates JF, Stone ER. The risk construct. In: Yates JF, editor. Risk-taking behavior. Chichester: John Wiley; 1992. p. 1-25.

25. Black S, Rappuoli R. A crisis of public confidence in vaccines. Sci Transl Med. 2010;2(61):61mr1, https://doi.org/10.1126/ scitranslmed.3001738.

26. Leask J. Target the fence-sitters. Nature. 2011;473:443-5, https://doi.org/10.1038/473443a.

27. Larson HJ, Jarrett C, Eckersberger E, Smith DMD, Paterson $\mathrm{P}$. Understanding vaccine hesitancy around vaccines and vaccination from a global perspective: A systematic review of published literature, 2007-2012. Vaccine. 2014;32(19): 2150-9, https://doi.org/10.1016/j.vaccine.2014.01.081.

28. Leask J, Kinnersly P. Physician communication with vaccinehesitant parents: The start, not the end, of the story. Pediatrics. 2015;136:180-2, https://doi.org/10.1542/peds.2015-1382.

29. Dubé E, MacDonald N. Managing the risks of vaccine hesitancy and refusals. Lancet Infect Dis. 2016;16:518-9, https:// doi.org/10.1016/S1473-3099(16)00028-1.

30. Fedeli U,Zanetti C, Saia B. Susceptibility of healthcare workers to measles, mumps rubella and varicella. J Hosp Infect. 2002;51(2):133-5, https://doi.org/10.1053/jhin.2002.1222.

31. Chodick G, Ashkenazi S, Livni G, Lerman Y. Cost-effectiveness of varicella vaccination of healthcare workers. Vaccine. 2005;23(43):5064-72, https://doi.org/10.1016/j.vaccine.2005.06.004.

32. Celikbas A, Ergonul O, Aksaray S, Tuygun N, Esener H, Tanir G, et al. Measles, rubella, mumps, and varicella sero- 
prevalence among health care workers in Turkey: Is prevaccination screening cost-effective? Am J Infect Control. 2006;34(9):583-7, https://doi.org/10.1016/j.ajic.2006.04.213.

33. Rachiotis G, Mouchtouri VA, Kremastinou J, Gourgoulianis $\mathrm{K}$, Hadjichristodoulou C. Low acceptance of vaccination against the 2009 pandemic influenza A(H1N1) among healthcare workers in Greece. Euro Surveill. 2010;15(6):19486.

34. Bouhour D, Gavazzi G, Gaillat J, Gajdos V, Loulergue P, Paccalin M, et al. Survey of vaccination policies in French healthcare institutions. Med Mal Infect. 2012;42(4):161-6, https://doi.org/10.1016/j.medmal.2011.11.003.

35. Maltezou H, Wicker S. Measles in health-care settings. Am J Infect Control. 2013;41(7):661-3, https://doi.org/10.1016/ j.ajic.2012.09.017.

36. Bonaccorsi G, Lorini C, Santomauro F, Guarducci S, Pellegrino E, Puggelli F, et al. Predictive factors associated with the acceptance of pandemic and seasonal influenza vaccination in health care workers and students in Tuscany, Central Italy. Hum Vaccin Immunother. 2013;9(12): 2603-12, https://doi.org/10.4161/hv.26036.

37. Pulcini C, Massin S, Launay O, Verger P. Knowledge, attitudes, beliefs and practices of general practitioners towards measles and MMR vaccination in southeastern France in 2012. Clin Microbiol Infect. 2014;20(1):38-43, https://doi. org/10.1111/1469-0691.12194.

38. Jarrett C, Wilson R, O'Leary M, Eckersberger E, Larson HJ, SAGE Working Group on Vaccine Hesitancy. Strategies for addressing vaccine hesitancy - A systematic review. Vaccine. 2015;33(34):4180-90, https://doi.org/10.1016/j.vaccine.2015.04.040.

39. Bonaccorsi G, Santomauro F, Porchia B, Niccolai G, Pellegrino E, Bonanni P, et al. Beliefs and opinions of health care workers and students regarding influenza and influenza vaccination in Tuscany, Central Italy. Vaccines (Basel). 2015;3(1):137-47, https://doi.org/10.3390/vaccines3010137.

40. Giannattasio A, Mariano M, Romano R, Chiatto F, Liguoro I, Borgia $\mathrm{G}$, et al. Sustained low influenza vaccination in health care workers after H1N1 pandemic: A cross sectional study in an Italian health care setting for at-risk patients. BMC Infect Dis. 2015:15:329, https://doi.org/10.1186/s12 879-015-1090-x.

41. Lugo NR. Will carrots or sticks raise influenza immunization rates of health care personnel? Am J Infect Control. 2007;35(1):1-6, https://doi.org/10.1016/j.ajic.2006.10.004.

42. Awali RA, Samuel PS, Marwaha B, Ahmad N, Gupta P, Kumar V, et al. Understanding health care personnel's attitudes toward mandatory influenza vaccination. Am J Infect Control. 2014;42(6):649-52, https://doi.org/10.1016/j.ajic. 2014.02.025.

43. Alicino C, Iudici R, Barberis I, Paganino C, Cacciani R, Zacconi $\mathrm{M}$, et al. Influenza vaccination among healthcare workers in Italy. Hum Vaccin Immunother. 2014;11(1):95-100, https://doi.org/10.4161/hv.34362.

44. Carrillo-Santisteve P, Lopalco PL. Measles still spreads in Europe: Who is responsible for the failure to vaccinate? Clin Microbiol Infect. 2012;18:50-6, https://doi.org/10.1111/ j.1469-0691.2012.03982.x.

45. Lopalco PL, Martin R. Measles still spreads in Europe: Who is responsible for the failure to vaccinate? Euro Surveill. 2010;15(17):19557.

46. Barbadoro P, Marigliano A, di Tondo E, de Paolis M, Martini E, Prospero E, et al. Measles among healthcare workers in a teaching hospital in central Italy. J Occup Health. 2012;54:336-9, https://doi.org/10.1539/joh.12-0016-BR.

47. Tafuri S, Gallone MS, Cappelli MG, Martinelli D, Prato R, Germinario C. Addressing the anti-vaccination movement and the role of HCWs. Vaccine. 2014;32(38):4860-5, https:// doi.org/10.1016/j.vaccine.2013.11.006.

48. Barrière J, Vanjak D, Kriegel I, Otto J, Peyrade F, Estève M, et al. Acceptance of the $2009 \mathrm{~A}(\mathrm{H} 1 \mathrm{~N} 1)$ influenza vaccine among hospital workers in two French cancer centers. Vaccine. 2010;28(43):7030-4, https://doi.org/10.1016/j.vaccine.2010.08.021.

49. Maltezou HC, Gargalianos P, Nikolaidis P, Katerelos P, Tedoma N, Maltezos E, et al. Attitudes towards mandatory vaccination and vaccination coverage against vaccine- 
preventable diseases among health-care workers in tertiarycare hospitals. J Infect. 2012;64(3):319-24, https://doi.org/ 10.1016/j.jinf.2011.12.004.

50. Quach S, Pereira JA, Heidebrecht CL, Kwong JC, Guay M, Crowe $\mathrm{L}$, et al. Health care worker influenza immunization rates: The missing pieces of the puzzle. Am J Infect Control. 2013;41(8):685-90, https://doi.org/10.1016/j.ajic.2012.09.022.

51. Odone A, Riccò M, Morandi M, Borrini BM, Pasquarella C, Signorelli C. Epidemiology of tuberculosis in a lowincidence Italian region with high immigration rates: Differences between not Italy-born and Italy-born TB cases. BMC Public Health. 2011;11:376, https://doi.org/10.1186/14712458-11-376.

52. Spadea A, Unim B, Ursillo P, Saulle R, Giraldi G, Miccoli $S$, et al. [Effectiveness of a training course on influenza vaccination in changing medical students' and healthcare workers' attitudes towards vaccination]. Ig Sanita Pubbl. 2013;69(4):387-402. Italian.

53. Albano L, Matuozzo A, Marinelli P, di Giuseppe G. Knowledge, attitudes and behaviour of hospital health-care workers regarding influenza $\mathrm{A} / \mathrm{H} 1 \mathrm{~N} 1$ : A cross sectional survey. BMC Infect Dis. 2014;14:208, https://doi.org/10.1186/14712334-14-208.

54. Cadeddu C, di Thiene D, Ricciardi W, Boccia A, la Torre G. Knowledge about pandemic flu among Italian health care workers (HCWs) an Italian survey. J Prev Med Hyg. 2011; 52(3):127-30.

55. Boccia A, di Thiene D, de Giusti M, la Torre G. Seasonal and pandemic influenza: The role of communication and preventive strategies. J Prev Med Hyg. 2011;52(3):124-6.

56. Falato R, Ricciardi S, Franco G. [Influenza risk perception and vaccination attitude in medical and nursing students during the vaccination campaigns of 2007/2008 (seasonal influenza) and 2009/2010 (H1N1 influenza)]. Med Lav. 2011;102(2):208-15. Italian.

57. Bonfiglioli R, Vignoli M, Guglielmi D, Depolo M, Violante FS. Getting vaccinated or not getting vaccinated? Different reasons for getting vaccinated against seasonal or pandemic influenza. BMC Public Health. 2013;13:1221, https:// doi.org/10.1186/1471-2458-13-1221.

58. Witteman HO. Addressing vaccine hesitancy with values. Pediatrics. 2015;136(2):215-7, https://doi.org/10.1542/peds. 2015-0949.

59. Abbritti G, Apostoli P, Iavicoli S, Murgia N, Persechino B, Soleo L, et al. Needs, education and accreditation in occupational medicine in Italy. Int Arch Occup Environ Health. 2004;78(1):75-8, https://doi.org/10.1007/s00420-004-0552-z.

60. Ramistella E, Maviglia A. [Professional activity of "competent physician" actual troubles and future perspectives]. G Ital Med Lav Erg. 2010;32(4):441-4. Italian.

This work is available in Open Access model and licensed under a Creative Commons Attribution-NonCommercial 3.0 Poland License - http://creativecommons.org/ licenses/by-nc/3.0/pl/deed.en. 